\title{
Protective effect of Xin-Ji-Er-Kang on cardiovascular remodeling in high salt-induced hypertensive mice
}

\author{
GUANGYAO HUANG ${ }^{1}{ }^{*}$, PAN CHENG $^{1 *}$, LING DING $^{1}$, LI WANG $^{1}$, JUAN HU $^{1}$, YONGXUE ZHANG ${ }^{1}$, \\ GUOWEI CAI ${ }^{1}$, MEILING CHEN ${ }^{2}$, AIZONG SHEN ${ }^{3}$ and SHAN GAO ${ }^{1}$ \\ ${ }^{1}$ Department of Pharmacology, Basic Medical College, Anhui Medical University, Hefei, Anhui 230032; \\ ${ }^{2}$ Department of Pharmacy, Cancer Hospital, Chinese Academy of Sciences, Hefei 230031; \\ ${ }^{3}$ Department of Pharmacy, The First Affiliated Hospital of USTC, Division of Life Sciences and Medicine, \\ University of Science and Technology of China, Hefei, Anhui 230001, P.R. China
}

Received May 12, 2018; Accepted November 14, 2018

DOI: $10.3892 /$ etm.2018.7105

\begin{abstract}
The aim of the present study was to investigate the effects of Xin-Ji-Er-Kang (XJEK) on high salt-induced hypertensive mice. Mice with high-salt diet-induced hypertension were divided into four groups: Control (standard diet alone for 8 weeks), model (diet containing $8 \% \mathrm{NaCl}$ for 8 weeks and intragastric administration of distilled water for the last 4 weeks), XJEK + high-salt-treated (diet containing $8 \% \mathrm{NaCl}$ for 8 weeks and intragastric administration of XJEK for the last 4 weeks) and irbesartan + high-salt-treated (diet containing $8 \% \mathrm{NaCl}$ for 8 weeks with intragastric administration of irbesartan for the last 4 weeks). The hemodynamic index and cardiac pathological changes in the hypertensive mice were then examined. An aortic ring apparatus was used to detect acetylcholine-dependent endothelium relaxation function. Colorimetric analysis was applied to determine serum nitric oxide (NO), superoxide dismutase activity and malondialdehyde content; ELISA was employed to measure brain natriuretic peptide, serum angiotensin II (Ang II), endothelin-1 content and aldosterone; and immunohistochemistry was used to detect the expression of endothelial nitric oxide synthase (eNOS), interleukin (IL)-1 $\beta$, IL-10 and tumor necrosis factor (TNF)- $\alpha$ in cardiac tissues. XJEK improved the heart systolic and diastolic function, ameliorated hemodynamic parameters
\end{abstract}

Correspondence to: Professor Aizong Shen, Department of Pharmacy, The First Affiliated Hospital of USTC, Division of Life Sciences and Medicine, University of Science and Technology of China, 17 Lujiang Road, Hefei, Anhui 230001, P.R. China

E-mail: ahslyysaz@126.com

Professor Shan Gao, Department of Pharmacology, Basic Medical College, Anhui Medical University, 81 Meisham Road, Hefei, Anhui 230032, P.R. China

E-mail: gaoshan@ahmu.edu.cn

${ }^{*}$ Contributed equally

Key words: hypertension, cardiac remodeling, endothelial dysfunction and cardiovascular remodeling indices, blunted the cardiac pathological changes and improved endothelial dysfunction (ED) via boosting eNOS activity, promoting NO bioavailability and decreasing serum Ang II content. Furthermore, treatment with XJEK inhibited the increase of IL- $1 \beta$ and TNF- $\alpha$ expression and the decrease of IL-10 expression in cardiac tissues, and ameliorated oxidative stress status. Therefore, XJEK exerted protective effects against high salt-induced hypertension and cardiovascular remodeling in mice via improving $\mathrm{ED}$, restoring pro- and anti-inflammatory factor balance and decreasing oxidative stress.

\section{Introduction}

Hypertension is a common disorder that affects $\sim 25 \%$ of the adult population (1). Hypertension induces abnormal blood dynamics and sugar and fat metabolic disorders, and also exerts negative effects on target organs such as the heart, brain and kidney. It has also been demonstrated that arterial hypertension accounts for 9.7 million fatalities annually, which is $>50 \%$ of the 17 million deaths resulting from various cardiovascular diseases (2). Epidemiological and interventional studies have demonstrated that the interactions between multiple factors, environmental as well as genetic, may lead to the development of high blood pressure $(3,4)$, and have revealed an evident association between high-salt dietary intake and hypertension (3).

A high-salt diet is known to be associated with increased arterial pressure; hence, high dietary salt intake is considered to be the main cause of cardiovascular, cerebrovascular and renal morbidity and mortality. Furthermore, progress in agriculture and farming has given rise to a constant growth in high salt consumption over the past several centuries (5). With the development of modern food processing and increasing popularity of high-salt fast food in recent decades, our daily intake of salt is markedly higher than what is required to maintain the normal physiological functions of sodium. Thus, high-salt diet is a major risk factor for the pathogenesis and progression of hypertension in modern society (6). Accumulating evidence indicates that the mechanism of high salt-induced hypertension may include expanded blood volume, increased blood flow and, ultimately, hypertension (7). Furthermore, as 
numerous studies indicate, high dietary salt intake poses a threat to target organs, increasing the risk of early morbidity and mortality, in addition to its impact on blood pressure, and clinical data also confirm that multiple factors likely contribute to high salt-induced hypertension (2). However, their exact interplay has not been fully elucidated, indicating that there may be additional factors underlying high salt-induced hypertension and cardiovascular remodeling; thus, further investigation is required.

Endothelial dysfunction (ED), which is considered to be implicated in the pathogenesis and progression of hypertensive heart disease (8), is typically manifested by reduced nitric oxide (NO) bioavailability, and its underlying mechanism may involve loss of endothelial nitric oxide synthase (eNOS) and cofactor tetrahydrobiopterin (BH4), hence leading to uncoupling of eNOS, due to which the enzyme produces superoxide anion rather than NO, further aggravating oxidative stress (OS) and inducing vascular pathogenesis (9). Roeleveld et al (10) previously presented evidence that endothelium-dependent dilation due to acetylcholine (ACh) in aortic segments from animals on high-salt diet was terminated by the inhibition of NOS with an L-arginine analog; however, these responses were only slightly inhibited in rats on a low-salt diet. More recent studies further demonstrated that the endothelial capacity for agonist-induced NO release was inhibited following high-salt intake for only 3 days $(11,12)$, which indicates that defects in the response to or production of NO may be implicated in salt-sensitive hypertension. In addition to decreasing NO bioavailability, ED also augments the release of angiotensin II (Ang II) and endothelin-1 (ET-1), accompanied by increasing superoxide anion $\left(\mathrm{O}_{2}{ }^{-}\right)$production via the angiotensin type 1-ETA/NADPH oxidase pathway (13-15), which further aggravates ED and OS. Hypertension has been recently viewed as a low-grade inflammatory disease, in which adaptive immunity is a critical mediator, with the components of both the innate and adaptive immune system contributing to its pathogenesis (16). Accumulation of macrophages and $\mathrm{T}$ cells has been observed in the perivascular fat, heart and kidney of hypertensive patients, as well as in hypertensive experimental animals (17). Notably, numerous studies (18-20) have explored the effect of Ang II on inducing inflammation in hypertension and other diseases, demonstrating the potential role of increased Ang II levels in several disorders and the effect of Ang II on promoting OS, resulting in inflammation, vascular dysfunction and target organ damage.

Traditional Chinese Medicine (TCM) has been used in China for $>2,000$ years and it has been one of the most enduring and widely tested alternative medicines worldwide. Due to its general acceptance and satisfactory efficacy, TCM has been attracting increasing scientific interest (21). Xin-Ji-Er-Kang (XJEK), which is a topical Chinese herbal medicine, is a representative TCM compound and is derived from 14 herbal medicines, including Panax ginseng C.A.Mey., Astragalus mongholicus Bunge, Ophiopogon japonicus (Thunb.) Ker-Gawl. and Polygonatum odoratum (Mill.) Druce. Clinical studies and basic research have both indicated the therapeutic effect of XJEK on coronary heart disease and experimental hypertension via decreasing OS, enhancing antioxidant activity and protecting the endothelium $(8,22)$.
The aim of the present study was to determine whether the chronic intake of XJEK ameliorates hypertension induced by a high-salt diet and elucidate the underlying mechanism, focusing on the involvement of ED and inflammation.

\section{Materials and methods}

Animals. A total of 40 Kunming male mice (age, 7-8 weeks; weight $20 \pm 2 \mathrm{~g}$ ) were obtained from Shanghai SLAC Laboratory Animal Co., Ltd. [Shanghai, China; certificate no. SCXK (HU) 2012-0002] and kept in the animal facility of Anhui Medical University (Hefei, China). All animals were handled strictly according to the rules and regulations outlined in the National Institutes of Health Guide for the Care and Use of Laboratory Animals (NIH Publications no. 8023, revision 1978 (23), and approval was granted from the Animal Care and Use Committee of Anhui Medical University. The mice were kept under standard conditions (temperature, $24^{\circ} \mathrm{C}$; humidity, $55 \pm 5 \%$ ) with a 12 -h dark/light cycle in solid-bottomed polypropylene cages and had access to commercial mouse chew and tap water ad libitum. After allowing the mice to acclimatize for 3 days, hypertension was induced by high-salt intake, as described previously (24).

Chemicals. XJEK, which is composed of 14 diversified medicinal herbs, as previously reported (8), was purchased from Nanjing Pharmaceutical Hefei Pharmacy Chain Co., Ltd. (Hefei, China), and irbesartan was purchased from Jiangsu Hengrui Medicine Co., Ltd. (Lianyungang, China; H20000513).

Induction of hypertension in mice and experimental design. Mice were randomized into four groups ( $\mathrm{n}=10$ per group) and the hypertension model was successfully induced (confirmed by measuring systolic blood pressure $\geq 130 \mathrm{mmHg}$ ) by a high-salt $(8 \% \mathrm{NaCl})$ diet for 8 weeks. The groups were as follows: i) Control group: 10 mice were fed a standard diet alone for 8 weeks; ii) model group: 10 mice were fed a diet containing $8 \% \mathrm{NaCl}$ for 8 weeks and were intragastrically administered distilled water for the last 4 weeks; iii) XJEK + high-salt-treated group: 10 mice were fed a diet containing $8 \% \mathrm{NaCl}$ for 8 weeks and received intragastric administration of XJEK $7.5 \mathrm{~g} / \mathrm{kg} /$ day for the last 4 weeks; and iv) irbesartan + high-salt-treated group: 10 mice were fed a diet containing $8 \% \mathrm{NaCl}$ for 8 weeks with intragastric administration of irbesartan $5 \mathrm{mg} / \mathrm{kg} /$ day for the last 4 weeks.

Measurement of systolic blood pressure (SBP). SBP was measured using the tail-cuff method (ALC-NIBP; Shanghai Alcott Biotech Co., Ltd., Shanghai China). The basal blood pressure of each group was recorded prior to the experiment and then once weekly during the following 8 weeks; all measurements were handled by the same person at the same time of day. Prior to measurement, the mice were kept in a warm environment $\left(27^{\circ} \mathrm{C}\right)$ for $30 \mathrm{~min}$ for the assessment of tail artery pulsations and a steady pulse level. The mean number of SBP measurements was 20.

Hemodynamics and cardiac remodeling index. The mice were anesthetized with $10 \%$ chloral hydrate $(300 \mathrm{mg} / \mathrm{kg}$, 
intraperitoneal; cat. no. CC3431-250G; Beijing Cool Laibo Technology Co., Ltd., Beijing, China), the right carotid artery was cannulated with a catheter (Transonic Scisense, Inc., London, ON, Canada) connected to an admittance control unit, and then the catheter was advanced along the right coronary artery and inserted into the left ventricle. The signals were registered on a four-channel acquisition system (BL420S; Chengdu Taimeng Software Co. Ltd., Chengdu, China). The admittance catheters were soaked for $30 \mathrm{~min}$ in Alconox prior to insertion into the common carotid artery according to the instructions of the manufacturer (Transonic Scisense, Inc.) The left ventricular systolic pressure (LVSP), left ventricular end-diastolic pressure (LVEDP) and the increase rate of the left ventricular pressure $\left( \pm d \mathrm{p} / d \mathrm{t}_{\max }\right)$ were recorded accordingly.

Blood and tissue sampling. Chloral hydrate $(300 \mathrm{mg} / \mathrm{kg})$ was given to mice anesthetized by intraperitoneal injection. Blood ( $\sim 1 \mathrm{ml})$ was collected from the heart into anticoagulant-coated tubes and immediately centrifuged at 4,000 x $\mathrm{g}$ for $10 \mathrm{~min}$ at $4^{\circ} \mathrm{C}$, and the serum was preserved at $-80^{\circ} \mathrm{C}$ for future analysis. Next, the mice were sacrificed via exsanguination. The thoracic cavity was opened to expose the still-beating heart. Hearts and aortic tissue were then harvested. The hearts were rinsed in ice-cold $0.9 \% \mathrm{NaCl}$ solution, photographed, blotted and weighed, and the heart weight index [heart weight (HW)/body weight $(\mathrm{BW})$ ] was calculated. Heart samples were divided into two parts, each of which was $\sim 5 \mathrm{~mm}$ thick. Aortic samples (4-5 $\mathrm{mm}$ in length) were placed in Krebs solution (composition detailed below) for further use.

Isolated vascular ring experiments. The thoracic aorta was excised immediately following the opening of the thoracic cavity. Transverse rings (4-5 $\mathrm{mm}$ in length) were cut, followed by removal of loose connective tissues, and all vessel rings were suspended in organ baths containing Krebs solution of the following composition $(\mathrm{mM})$ : $\mathrm{NaCl}, 118 ; \mathrm{KCl}, 4.75$; $\mathrm{NaHCO}_{3}, 25 ; \mathrm{MgSO}_{4}, 1.2 ; \mathrm{CaCl}_{2}, 2 ; \mathrm{KH}_{2} \mathrm{PO}_{4}, 1.2$; and glucose, 11. Krebs solution was maintained at $37 \pm 1^{\circ} \mathrm{C}$ and injected with $95 \% \mathrm{O}_{2}: 5 \% \mathrm{CO}_{2}(\mathrm{pH} 7.4)$. This experiment had been previously performed for mouse aortic strips, and $0.5 \mathrm{~g}$ of tension was determined as optimal for this type of tissue (25). The rings underwent equilibration from 60-90 min, during which time warm Krebs solution was used to stretch and wash the tissues every $15 \mathrm{~min}$. The concentration-relaxation response curves to ACh (10-9-10-6M) were constructed for intact rings that were precontracted by $10-5 \mathrm{M}$ phenylephrine. Relaxant responses to ACh were expressed as a percentage of precontraction induced by phenylephrine.

Histological and morphological analyses of the heart and thoracic aorta. The heart apex was fixed for $48 \mathrm{~h}$ at $27^{\circ} \mathrm{C}$ by immersion in neutral $10 \%$ buffered formalin for histological analysis. Hematoxylin-eosin $\left(\mathrm{HE} ; 27^{\circ} \mathrm{C}\right.$ for $4 \mathrm{~h}$ ) and Van Gieson staining $\left(27^{\circ} \mathrm{C}\right.$ for $\left.4 \mathrm{~h}\right)$ were applied to observe the prepared $5-\mu \mathrm{m}$ paraffin sections. Subsequently, the myocyte cross-sectional area (CSA), perivascular collagen area (PVCA) and collagen volume fraction $(\mathrm{CVF})$ were quantitatively analyzed with ImageJ software (1.8.0; National Institutes of Health, Bethesda, MD, USA) in Leica inverted optical electron microscope (magnification, x400; Leica DM IL, DC 300; Leica
Microsystems GmbH, Wetzlar, Germany). The thoracic aortas were removed from mice, cleaned and fixed $\left(27^{\circ} \mathrm{C}\right.$ for $\left.48 \mathrm{~h}\right)$ in neutral $10 \%$ buffered formalin. Paraffin-embedded thoracic aorta samples were cut in 5- $\mu \mathrm{m}$ sections, dewaxed and stained $\left(27^{\circ} \mathrm{C}\right.$ for $\left.4 \mathrm{~h}\right)$ with $\mathrm{HE}$; then, the total aortic area (TAA), luminal area (LA), CSA, aortic radius (AR), luminal radius (L) and media thickness $(\mathrm{M})$ of the aorta were assessed with Image-Pro Plus (6.0; Media Cybernetics, Inc., Rockville, MD, USA) and the proportion of $\mathrm{M} / \mathrm{L}$ was calculated as previously described (25).

Measurement of serum NO, superoxide dismutase (SOD), malondialdehyde (MDA), ET-1, brain natriuretic peptide (BNP), Ang II and aldosterone content. NO activity was determined according to the method described by Veltkamp et al (26), in which most NO was instantly converted to nitrite $\left(\mathrm{NO}_{2}^{-}\right)$and nitrate $\left(\mathrm{NO}_{3}^{-}\right)$due to its instability in physiological solutions. The levels of $\mathrm{NO}_{2}{ }^{-} / \mathrm{NO}_{3}{ }^{-}$in the serum were measured with the application of an NO assay kit (A013-2; Nanjing Jiancheng Bioengineering Institute, Nanjing, China) according to the manufacturer's instructions. Under the effect of aspergillus nitrite reductase, nitrate briefly reverted to nitrite, and the Griess reagent was applied for measurement of the total nitrite. Spectrophotometry at $540 \mathrm{~nm}$ was employed to detect absorbance. ELISA was applied to assess the contents of ET-1 (H093, Nanjing Jiancheng Bioengineering Institute), Ang II (H185; Nanjing Jiancheng Bioengineering Institute), BNP (H166; Nanjing Jiancheng Bioengineering Institute) and aldosterone (H188; Nanjing Jiancheng Bioengineering Institute) according to the manufacturer's instructions.

The thiobarbituric acid reactive substances assay was adopted to detect the MDA content, strictly following the MDA assay kit's (TBA method) instructions (A003-1; Nanjing Jiancheng Bioengineering Institute, Nanjing, China) and the absorbance was measured at a wavelength of $532 \mathrm{~nm}$. Furthermore, the absorbance at $550 \mathrm{~nm}$ was detected using a SOD assay kit (A001-3; Nanjing Jiancheng Bioengineering Institute), to determine SOD activity.

Measurement of eNOS activity levels in the serum and cardiac tissue. eNOS activity in the serum and cardiac tissue was evaluated using ELISA (H195; Nanjing Jiancheng Bioengineering Institute) according to the manufacturer's instructions.

Immunohistochemistry for eNOS, interleukin (IL)-1 $\beta$, tumor necrosis factor (TNF)- $\alpha$ and IL-10. Immunohistochemical staining was performed by applying the Ultra Sensitive S-P kit produced by Wuhan Boster Biological Technology, Ltd. (Wuhan, China) in accordance with the manufacturer's instructions. Formalin (10\%) was used for fixation at $24^{\circ} \mathrm{C}$ for $48 \mathrm{~h}$, and the $5 \mu \mathrm{m}$ paraffin sections were observed. Deparaffinization of sections was performed in $10 \mathrm{mM}$ sodium citrate buffer (pH 6.0), followed by microwave treatment for $10 \mathrm{~min}$ twice. The sections were then incubated with endogenous peroxidase blocking solution (3\% hydrogen peroxide; AR1108; Whuan Boster Biological Technology Ltd., Wuhan, China) for $10 \mathrm{~min}$ at room temperature. Primary rabbit polyclonal antibodies against eNOS (1:100; ab76198, Abcam, Cambridge, UK) and polyclonal antibodies against IL-1 $\beta$ (1:200; 12242; Cell Signaling Technology, Inc., Danvers, MA, USA), TNF- $\alpha$ 
(1:200; ab6671; Abcam) and IL-10 (1:200; 20850-1-AP; ProteinTech Group, Inc., Chicago, IL, USA) were added and incubated at $4^{\circ} \mathrm{C}$ for $18 \mathrm{~h}$. The sections were washed three times using PBS, and then incubated $\left(37^{\circ} \mathrm{C}\right)$ with biotin-conjugated anti-rabbit (1:100; SPN-9001; OriGene Technologies, Inc., Rockville, MD, USA) and anti-mouse (1:100, SPN-9002, OriGene Technologies, Inc.) secondary antibody for $10 \mathrm{~min}$. The sections were again washed three times with PBS, followed by incubation with streptavidin-peroxidase for $10 \mathrm{~min}$ at $37^{\circ} \mathrm{C}$ and another three washes with PBS. Following haematoxylin counterstaining $\left(27^{\circ} \mathrm{C}\right)$ for $10 \mathrm{~min}$, the sections were incubated $\left(27^{\circ} \mathrm{C}\right)$ in diaminobenzidine for $5 \mathrm{~min}$. At the same time, the negative group was constructed where one slice was selected from each group and was treated as aforementioned, but with PBS instead of antibodies. Leica inverted optical electron microscope (magnification, x400; Leica DM IL, DC 300; Leica Microsystems GmbH, Wetzlar, Germany) was used to capture images.

Western blotting for IL-1 $\beta, T N F-\alpha$ and IL-10. Frozen heart tissue specimens $(20 \mathrm{mg}$ ) were added to $990 \mu 1$ radioimmunoprecipitation assay lysis buffer (CW2334S; Beijing ComWin Biotech Co., Ltd., Beijing, China) and $10 \mu \mathrm{l}$ protease inhibitor (CW2383S; Beijing ComWin Biotech Co., Ltd.). The tissues were ground and the tissue homogenate was centrifuged at $12,000 \mathrm{x} \mathrm{g}$ for $15 \mathrm{~min}$ at $4^{\circ} \mathrm{C}$. The supernatant was collected and protein concentration was determined using a $\mathrm{BCA}$ Protein Assay kit (P0010; Beyotime Institute of Biotechnology, Haimen, China). Equal amounts $(10 \mu \mathrm{l})$ of loaded proteins were separated by $10 \%$ SDS-PAGE and transferred to polyvinylidene difluoride membranes, which were then blocked at room temperature for $1 \mathrm{~h}$ with 5\% dry skimmed milk in Tris-buffered saline containing 1\% Tween-20 (TBST). The membranes were incubated with antibodies against glucocorticoid receptor, IL-1 $\beta(1: 1,000)$, TNF- $\alpha(1: 500)$, IL-10 $(1: 1,000)$ and GAPDH $(1: 10,000)$ overnight at $4^{\circ} \mathrm{C}$. GAPDH antibodies (ab181602) were purchased from Abcam. Membranes were washed with TBST three times, 5 min each. IL-1 $\beta$, TNF- $\alpha$ and IL-10 were incubated (at $27^{\circ} \mathrm{C}$ ) with anti-rabbit immunoglobulin (Ig)G secondary antibody conjugated to horseradish peroxidase (HRP) for $1 \mathrm{~h}$ (1:10,000; ab7090; Abcam), and eNOS and GAPDH were incubated (at $27^{\circ} \mathrm{C}$ ) with anti-mouse IgG secondary antibody conjugated to HRP for $1 \mathrm{~h}(1: 10,000$; ab97040; Abcam). Following extensive washing, the protein bands were detected by enhanced chemiluminescence reagents (ECL kit; GE Healthcare Life Sciences, Little Chalfont, UK). The Chemi Q4800 mini Imaging System (Bioshine, Shanghai, China) was used to visualize protein bands, and densitometry analysis was performed with ImageJ software. The density of each immunoreactive band was normalized to the density of its corresponding band of GAPDH.

Statistical analysis. In the present study, all data are from at least three independent experiments and are expressed as the mean \pm standard deviation. Data were analyzed by one-way analysis of variance to test the significance of differences between the control and drug-treated groups. Comparisons between multiple groups was performed using the Scheffe post hoc test. $\mathrm{P}<0.05$ was considered to indicate a statistically significant difference.

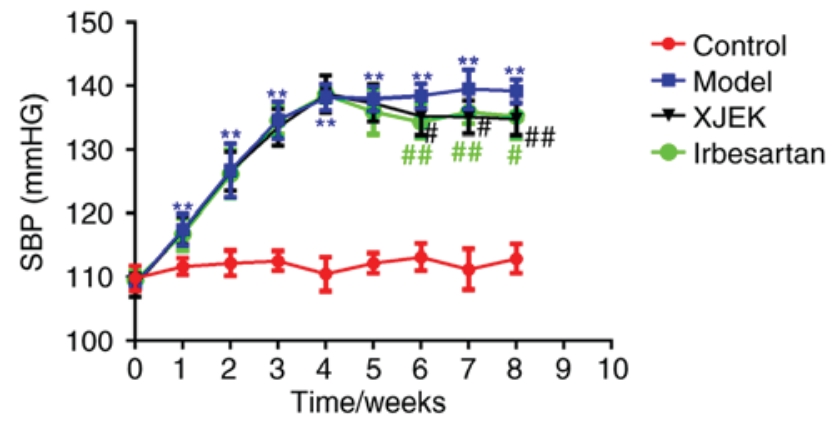

Figure 1. Development of SBP in the four experimental groups during an 8 -week period. A total of 9 time points of SBP were measured using tail-cuff apparatus measurement in each group. Data are presented as the mean \pm standard deviation, $\mathrm{n}=10$. $^{* *} \mathrm{P}<0.01$ vs. control group; ${ }^{\#} \mathrm{P}<0.05,{ }^{\# \#} \mathrm{P}<0.01$ vs. model group. SBP, systolic blood pressure; XJEK, Xin-Ji-Er-Kang.

\section{Results}

Effects of XJEK on SBP in high salt-induced hypertensive mice. Time-related changes in SBP among the four groups are presented in Fig. 1. No marked difference was observed in SBP among experimental groups at baseline. The high daily intake of salt for 8 weeks induced a marked elevation in SBP $(139.17 \pm 1.80 \mathrm{mmHg})$ in the model group compared with in the control group $(112.89 \pm 2.31 \mathrm{mmHg} ; \mathrm{P}<0.01)$, whereas administration of XJEK for the last 4 weeks markedly decreased SBP, compared with the model $(134.81 \pm 2.53 ; \mathrm{P}<0.01)$. The SBP in hypertensive mice on irbesartan treatment was also downregulated compared with in the model group $(135.25 \pm 3.54 ; \mathrm{P}<0.01)$.

Effects of XJEK on hemodynamic parameters in high salt-induced hypertensive mice. In all groups, in vivo left ventricular function was evaluated at the end of the 8 weeks. As indicated in Table I, the systolic cardiac parameters in the model group, such as LVSP $+d \mathrm{p} / d \mathrm{t}_{\max }$, and diastolic cardiac parameters $\left(-d \mathrm{p} / d \mathrm{t}_{\max }\right)$, were all raised in the model group compared with the control, which was reversed by XJEK treatment. Similar results were achieved in the positive control group with irbesartan treatment.

Effects of XJEK on cardiac remodeling in high salt-induced hypertensive mice. The histological study of the hearts of the experimentally-induced hypertensive mice in the model group demonstrated that myocyte CSA, and the levels of CVF was all markedly increased compared with those in the control group ( $\mathrm{P}<0.01$; Fig. 2A-C). Treatment with XJEK for 4 weeks reversed these pathological changes $(\mathrm{P}<0.01)$, as did irbesartan in the positive control group $(\mathrm{P}<0.05)$. Compared with in the control group, the HW/BW ratio was increased in the model group, reflecting cardiac hypertrophy ( $\mathrm{P}<0.01$; Fig. 2D).

BNP may be associated with cardiovascular disorders, even at levels far below contemporary thresholds for diagnosing heart failure. The present study revealed no significant difference in the level of BNP among the four experimental groups, which may be attributed to the cardiac compensatory phase, which protects against high-salt diet-induced damage (Fig. 2E). The level of PVCA in the model group was significantly higher than that in the control group, but was reversed in the XJEK group $(\mathrm{P}<0.01$; Fig. 3$)$. 
Table I. Effects of XJEK on cardiac function in high-salt induced hypertensive mice.

\begin{tabular}{lcccc}
\hline Group & LVSP $(\mathrm{mmHg})$ & LVEDP $(\mathrm{mmHg})$ & $+d \mathrm{p} / d \mathrm{t}_{\max }(\mathrm{mmHg} / \mathrm{sec})$ & $-d \mathrm{p} / d \mathrm{t}_{\max }(\mathrm{mmHg} / \mathrm{sec})$ \\
\hline Control & $83.13 \pm 8.59$ & $-3.78 \pm 5.85$ & $4,147.56 \pm 715.84$ & $-3,178.7 \pm 673.53$ \\
Model & $102.05 \pm 20.96^{\mathrm{a}}$ & $-2.63 \pm 5.31$ & $5,315.25 \pm 1,122.92^{\mathrm{a}}$ & $-4,343.32 \pm 1,049.13^{\mathrm{a}}$ \\
XJEK & $88.52 \pm 8.30$ & $-1.26 \pm 3.90$ & $4,275.33 \pm 474.32^{\mathrm{b}}$ & $-3,497.60 \pm 479.50^{\mathrm{b}}$ \\
Irbesartan & $96.84 \pm 14.87$ & $-3.59 \pm 6.82$ & $4,958.59 \pm 922.37$ & $-4,250.01 \pm 756.12$ \\
\hline
\end{tabular}

Data are presented as the mean \pm standard deviation, $\mathrm{n}=10$. XJEK, Xin-Ji-Er-Kang; LVSP, left ventricular systolic pressure; LVEDP, left ventricular end-diastolic pressure; $+d \mathrm{p} / d \mathrm{t}_{\max }$, maximal rate of left ventricular systolic pressure; $-d \mathrm{p} / d \mathrm{t}_{\max }$, maximal rate of left ventricular diastolic pressure. ${ }^{\mathrm{P}} \mathrm{P}<0.05$ vs. control group; ${ }^{\mathrm{b}} \mathrm{P}<0.05$ vs. model group.

A a-1

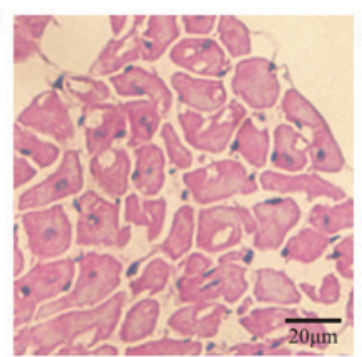

B b-1

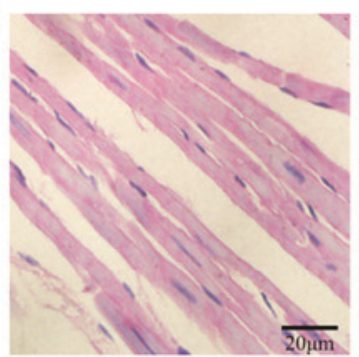

a-2

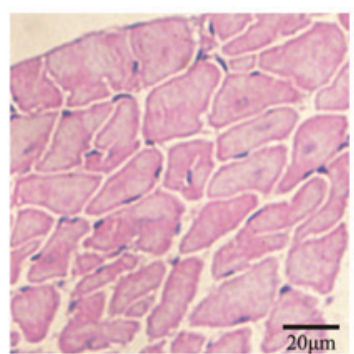

b-2

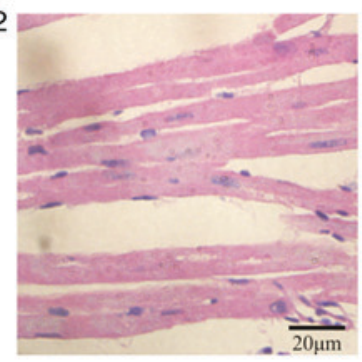

a-3

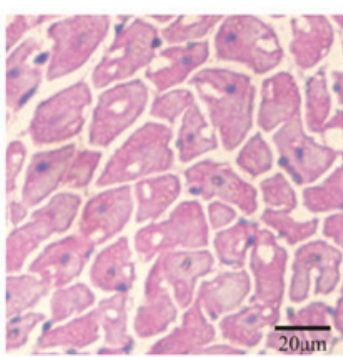

b-3

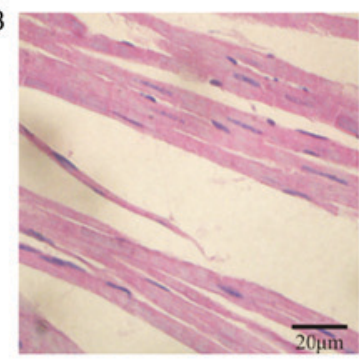

a-4
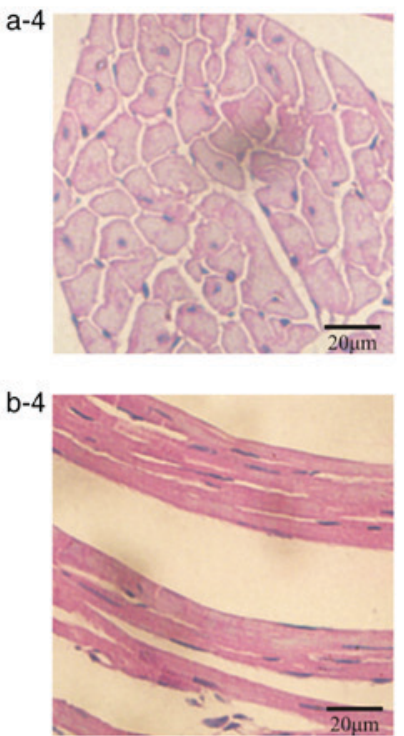
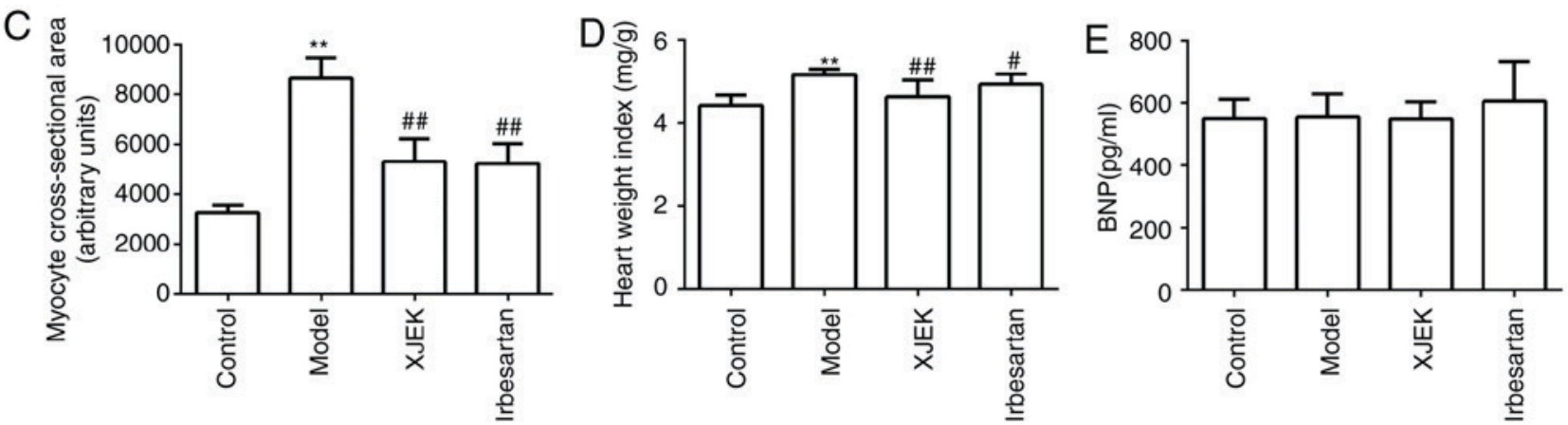

Figure 2. Effects of XJEK on HW/BW, myocyte CSA in high-salt induced hypertensive mice. (A) Representative figure of myocyte cross-section (HE staining, x400). (B) Representative figure of myocyte long axis (HE staining, x400). 1: Control group; 2: Model group; 3: XJEK + high-salt-treated group; 4: Irbesartan + high-salt-treated group. (C) Quantified results of myocyte CSA. (D) Quantified results of HW/BW. (E) Plasma BNP content in high-salt induced hypertensive mice. Data are presented as the mean \pm standard deviation, $\mathrm{n}=10 .{ }^{* *} \mathrm{P}<0.01$ vs. control group; ${ }^{*} \mathrm{P}<0.05$, ${ }^{\# \#} \mathrm{P}<0.01$ vs. model group. $\mathrm{XJEK}$, Xin-Ji-Er-Kang; HW/BW, heart weight/body weight; CSA, cross-sectional area; HE, hematoxylin and eosin; BNP, brain natriuretic peptide.

Effects of XJEK on aortic remodeling in high salt-induced hypertensive mice. The vascular remodeling of the upper thoracic aorta in mice on a high-salt diet was evaluated at the end of the 8th week. The TAA, LA, CSA, CSA/TAA, $A R, L$ and $M$ values and the $M / L$ ratio of the aorta in high salt-induced hypertensive mice were elevated compared with those in control mice, which was effectively reversed by XJEK and irbesartan intervention over the last 4 weeks (Fig. 4; Table II).
Effects of XJEK on ED in high salt-induced hypertensive mice. NO content and eNOS activity in the cardiac tissue and serum of model group mice were markedly decreased compared with those in the control group $(\mathrm{P}<0.05)$, whereas mice treated with XJEK or irbesartan exhibited increased NO and eNOS levels compared with in the model group $(\mathrm{P}<0.05$; Fig. 5).

The Ang II, ET-1 and aldosterone levels were detected 8 weeks later. The serum Ang II, ET-1 and aldosterone content was increased in hypertensive mice compared with that in the 

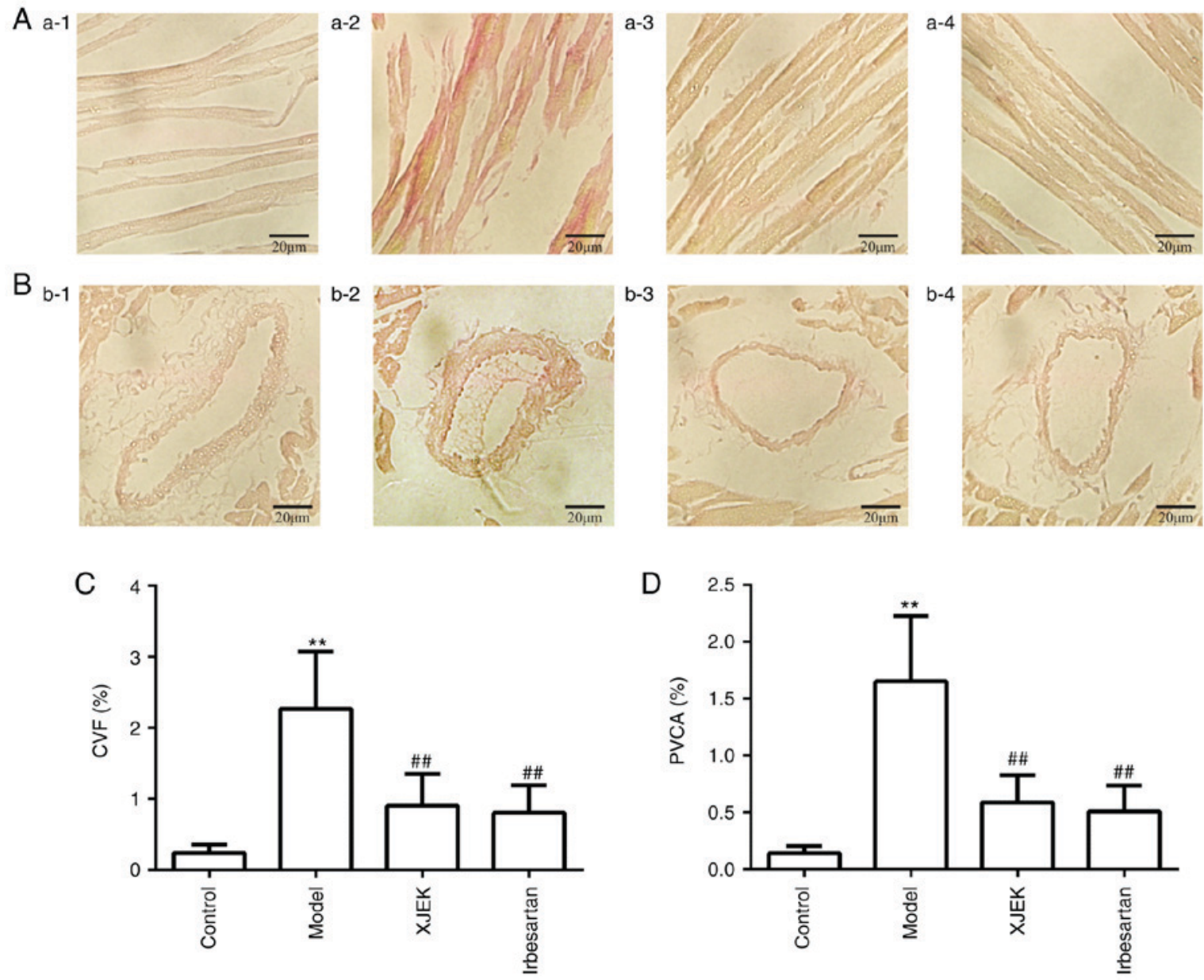

Figure 3. Effects of XJEK on CVF and PVCA in high-salt induced hypertensive mice. (A) Representative figure of myocardial fibrosis (VG staining, x400). (B) Representative figure of perivascular fibrosis (VG staining, $\mathrm{x} 400$ ). (C) Quantified results of myocardial fibrosis. (D) Quantified results of perivascular fibrosis. Data are presented as the mean \pm standard deviation, $n=10 .{ }^{* *} \mathrm{P}<0.01$ vs. control group; ${ }^{\# \#} \mathrm{P}<0.01$ vs. model group. XJEK, Xin-Ji-Er-Kang; $\mathrm{CVF}$, collagen volume fraction; PVCA, perivascular collagen area; VG, Van Gieson.

1

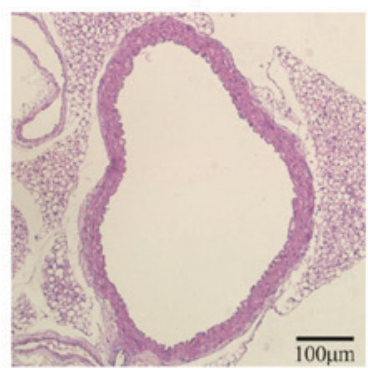

2

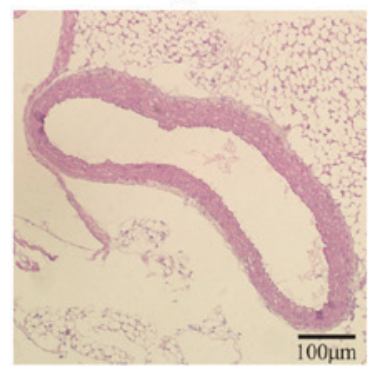

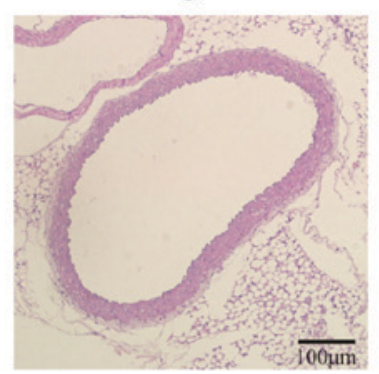

4

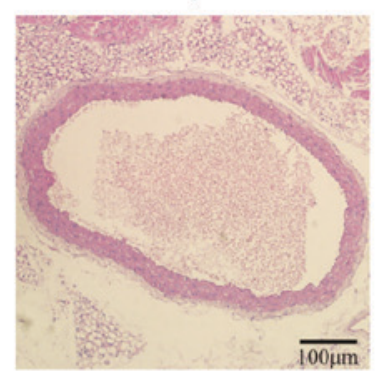

Figure 4. Representative images of aortic remodeling in different groups. Groups were divided as follows; 1: Control group; 2: Model group; 3: Xin-Ji-Er-Kang + high-salt-treated group; 4: Irbesartan + high-salt-treated group. Hematoxylin and eosin staining was used; original magnification, x100.

control group $(\mathrm{P}<0.01)$, but was markedly reduced following XJEK and irbesartan intervention $(\mathrm{P}<0.01$; Fig. 6).

Compared with those of the control group, the aortic rings of mice on a high-salt diet exhibited drastically decreased endothelium-dependent vasodilator responses to $\mathrm{ACh}$ in aortic segments stimulated by phenylephrine (Fig. 7). Compared with the model group, XJEK treatment markedly improved the vasodilation induced by $\mathrm{ACh}$ in the aortic rings of high salt-induced hypertensive mice, indicating that high salt-induced hypertension may lead to increased ED, whereas 4-week experimental therapy with XJEK ameliorated the ED induced by high-salt intake.

Effects of XJEK on inflammatory cytokine expression in high salt-induced hypertensive mice. The expression of IL-1 $\beta$ and TNF- $\alpha$ in cardiac tissues was markedly increased in the high-salt group compared with control group mice $(\mathrm{P}<0.01)$, while the increase in expression was inhibited by XJEK and irbesartan intervention ( $\mathrm{P}<0.01$; Fig. $8 \mathrm{~A}$ and $\mathrm{B})$. In high saltinduced hypertensive mice, the expression of IL-10 in cardiac 
tissues was reduced significantly compared with controls $(\mathrm{P}<0.01)$, but was then markedly increased with XJEK and irbesartan treatment compared with the model group $(\mathrm{P}<0.01$; Fig. 8C). The immunohistochemical results of IL-1 $\beta$, TNF- $\alpha$ and IL-10 are presented in Figs. 8D-F. Furthermore, the results of IL-1 $\beta$, TNF- $\alpha$ and IL-10 western blotting were consistent with those of immunohistochemistry $(\mathrm{P}<0.01$; Fig. 8G-L).

Effect of XJEK on serum SOD activity and MDA content in high salt-induced hypertensive mice. Compared with the control group, the SOD level was markedly decreased in the model group $(\mathrm{P}<0.01)$, as presented in Fig. 9A. By contrast, the serum MDA level was observably increased in the model group compared with that in the control group $(\mathrm{P}<0.05$; Fig. 9B). XJEK administration during the last 4 weeks markedly decreased MDA content $(\mathrm{P}<0.05)$ and enhanced serum SOD activity $(\mathrm{P}<0.01)$.

\section{Discussion}

Hypertension is the most common type of cardiovascular disease and the leading cause of mortality and disability worldwide (27). Experimental observations have demonstrated that a long-term high-salt diet may induce hypertension and renal injury in normal Sprague-Dawley rats and it was also found to be associated with $\operatorname{ED}(1,28,29)$. In accordance with previous reports, the present study demonstrated that a high-salt diet led to hypertension and cardiovascular remodeling in mice, manifested by the deterioration of cardiac hemodynamics, HW/BW index, cardiomyocyte CSA and longitudinal diameter, aortic wall thickness, TAA and media thickness. In addition, obvious $\mathrm{ED}$, OS and inflammatory status were observed in mice, clearly reflecting the association of high-salt diet with hypertension. Of note, treatment with XJEK markedly alleviated these pathophysiological changes. The dose of XJEK for the present study was based on the clinical dose, and was converted for mice according to pharmacology conversion formula (30). Furthermore, the dose of XJEK was considered based on our previous report $(31,32)$ and with minor modifications according to different animal models.

The endothelium has long been viewed as a protective biocompatible barrier between tissues and circulating blood, and it is also a key regulator of vascular homeostasis, due to the fact that it not only acts as a barrier, but serves as an active signal transducer that circulates influency, modifying the vessel wall phenotype (33). ED is a systemic pathological condition resulting from an imbalance between endothelium-dependent vasoconstriction and vasodilation, specifically associated with reduced NO production, downregulation of eNOS expression and reduced endothelium-dependent vasodilator response (34-36), upregulation of ET-1, and increased reactive oxygen species, cytokine and chemokine production (37). It has been established that environmental factors, such as high salt intake, contribute to vascular remodeling, ultimately leading to BP elevation and cardiovascular diseases, which often co-exist with a lack of $\mathrm{NO}$ (28) and overexpression of ET-1 (38). Normally, the renin-angiotensin II system (RAS) can effectively regulate arterial $\mathrm{BP}$ and $\mathrm{Na}^{+}$excretion, a process in which the peptide hormone Ang II serves an important role (39). Salt restriction may stimulate Ang II formation, while the high 


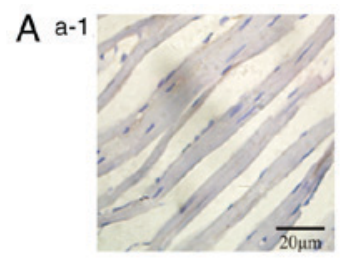

B
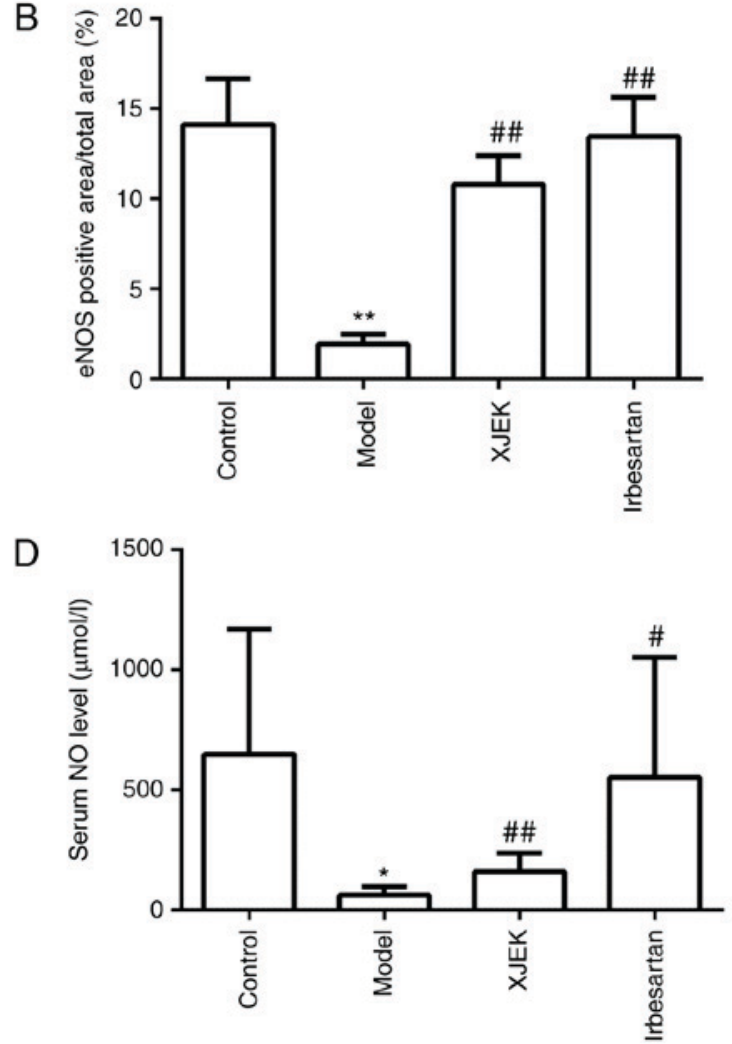
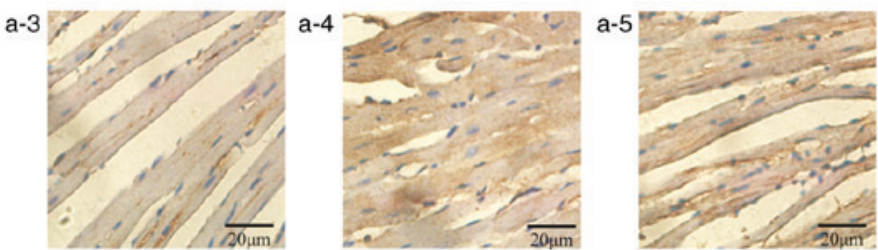

C

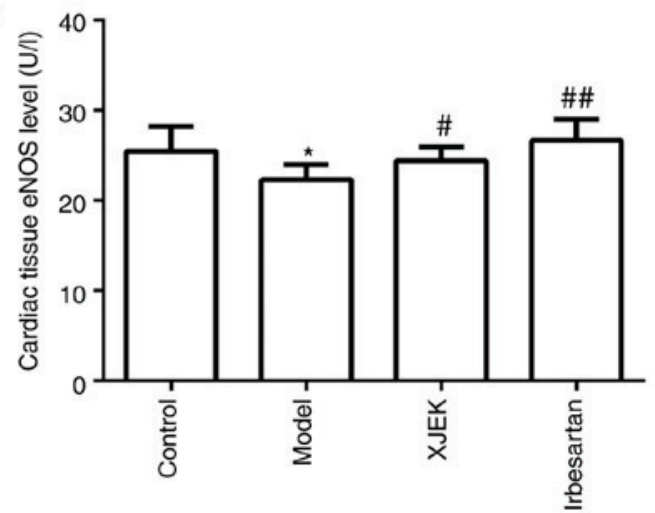

$\mathrm{E}$

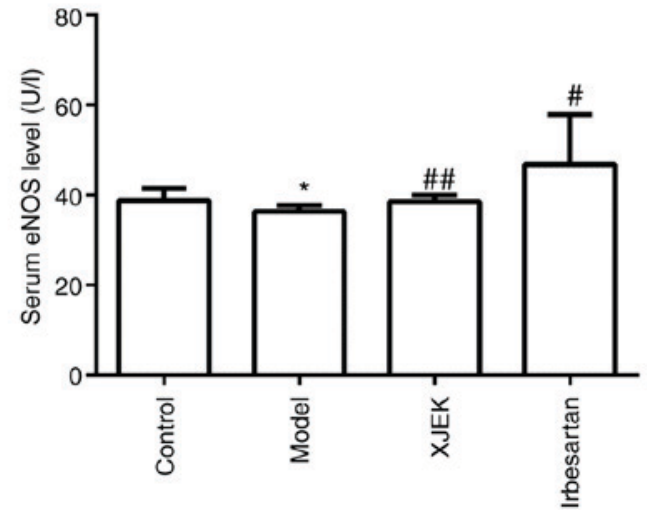

Figure 5. Effects of XJEK on serum NO content, eNOS activity in high-salt hypertensive mice. (A) Representative images of eNOS immunohistological staining in hearts (magnification, x400). 1: Negative group; 2: Control group; 3: Model group; 4: XJEK + high-salt-treated group; 5: Irbesartan + high-salt-treated group. (B) Quantified results of eNOS immunohistological staining and (C) cardiac tissue eNOS activity measured by ELISA. (D) Serum NO content by colorimetric analysis. (E) Serum eNOS activity measured by ELISA. Data are presented as the mean \pm standard deviation, $\mathrm{n}=10 .{ }^{*} \mathrm{P}<0.05,{ }^{* *} \mathrm{P}<0.01$ vs. control group; ${ }^{\#} \mathrm{P}<0.05,{ }^{\# \#} \mathrm{P}<0.01$ vs. model group. XJEK, Xin-Ji-Er-Kang; NO, nitric oxide; eNOS, endothelial nitric oxide synthase.
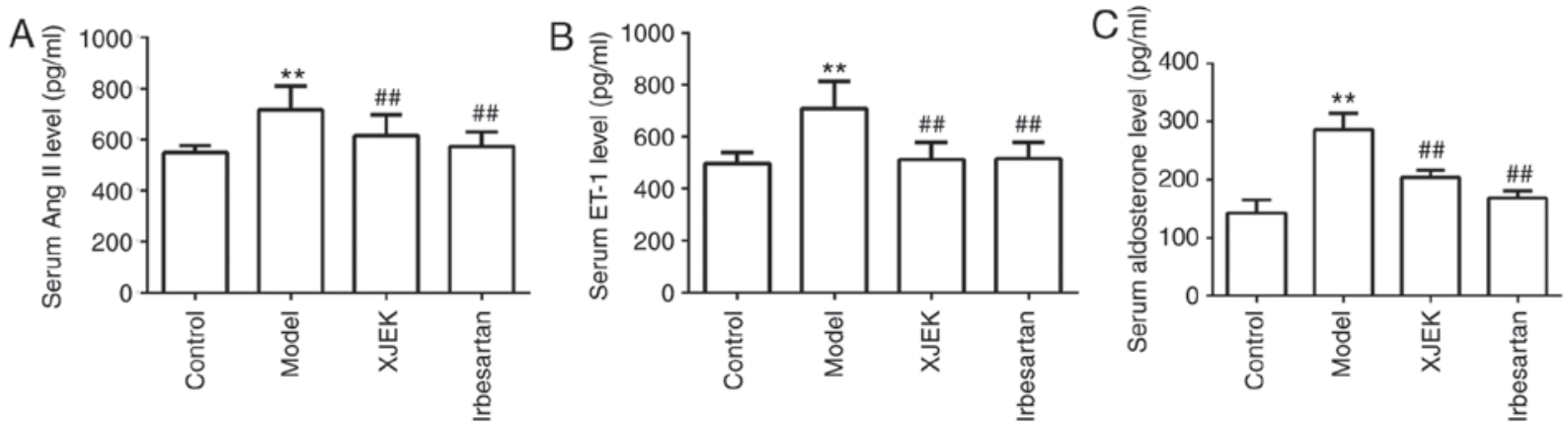

Figure 6. Effects of XJEK on serum Ang II content (A), ET-1 content (B) and aldosterone (C) in high-salt induced hypertensive mice. Data are presented as the mean \pm standard deviation, $n=10 .{ }^{* *} \mathrm{P}<0.01$ vs. control group; ${ }^{\# \prime} \mathrm{P}<0.01$ vs. model group. XJEK, Xin-Ji-Er-Kang; Ang II, angiotensin II; ET-1, endothelin 1 .

dietary salt intake suppresses it (20). However, the dysfunction of RAS and unusually increased Ang II levels account for numerous pathological conditions (39). Previous studies have demonstrated a correlation between ET-1 and Ang II, i.e., ET-1 enhances the activity of the angiotensin-converting enzyme, promoting the conversion of Ang I to Ang II, which then boosts the activity of the endothelin-converting enzyme $(40,41)$. Amiri et al (38) demonstrated that ET-1 overexpression associated with high salt consumption promoted ED and vascular remodeling of resistance vessels, and contributed to an increase in BP, mediated in part by endothelin type A and type B receptors. Abnormal elevation of Ang II and ET-1 


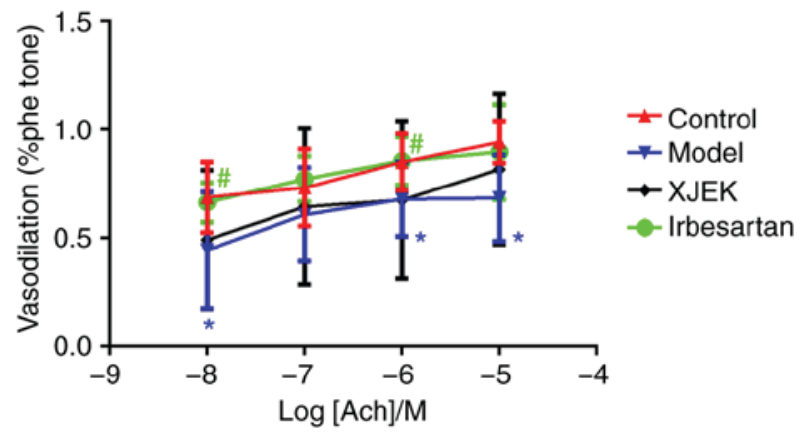

Figure 7. XJEK increased vasodilation of the thoracic aorta from high-salt induced hypertensive mice. Data are presented as the mean \pm standard deviation, $n=10$. ${ }^{*} \mathrm{P}<0.05$ vs. control group; ${ }^{*} \mathrm{P}<0.05$ vs. model group. XJEK, Xin-Ji-Er-Kang; Ach, acetylcholine.

stimulates $\mathrm{O}_{2}{ }^{--}$production by NADPH oxidase, and elevated $\mathrm{O}_{2}{ }^{--}$levels disturb normal signal transduction mechanisms in endothelial and vascular smooth muscle cells, and induce the production of more $\mathrm{O}_{2}{ }^{-}$by decreasing vascular levels of $\mathrm{BH} 4$, an important co-factor for NO production (42). The interaction between $\mathrm{O}_{2}{ }^{-}$and $\mathrm{NO}$ may lead to increased peroxynitrite $\left(\mathrm{ONOO}^{-}\right)$formation, which in turn results in further increase in $\mathrm{O}_{2}{ }^{-}$. This accelerates the oxidation of the NOS co-factor $\mathrm{BH}_{4}$ by $\mathrm{ONOO}^{-}$and leads to eNOS uncoupling, during which the catalytic activity of eNOS generates additional $\mathrm{O}_{2}{ }^{--}$instead of NO, leading to a vicious cycle of oxidative stress, which is a process referred to as eNOS uncoupling (43). The present study demonstrated that salt loading in mice led to significant ED, manifested by decreased serum NO availability and eNOS activity, increasing serum Ang II and ET-1 content, and leading to endothelium-dependent vasorelaxant dysfunction and an obvious OS status. Treatment with XJEK for 4 weeks improved high salt-induced ED, as was reflected by the amelioration of $\mathrm{NO}$-dependent artery relaxation and restoration of the balance between vasodilation (NO and eNOS) and vasoconstriction (Ang II and ET-1) factors. Under normal conditions, increased dietary salt intake suppresses plasma renin activity, leading to suppression of circulating Ang II levels and reduced plasma levels of aldosterone, resulting in reduced reabsorption of $\mathrm{Na}^{+}$by the renal tubules to facilitate $\mathrm{Na}^{+}$excretion and maintain blood volume. Ang II also stimulates the secretion of aldosterone in the adrenal cortex, causing retention of water and sodium in the body and increasing BP (44). In the present study, the aldosterone content was increased in the serum of model mice, while it was significantly decreased in the serum of mice treated with XJEK. Furthermore, Ang II accounts for the downregulation of MDA content and the upregulation of SOD activity in the serum, ameliorating OS status.

It has been indicated previously that the immune system and inflammatory response are also crucial for the pathogenesis of hypertension, in which the innate and adaptive immune cells transmigrate and accumulate in the interstitium of affected tissues, where they trigger cytokine release and activation, causing remodeling as well as impaired cardiovascular function and target organ injury (45). Cytokines represent a diverse group of various soluble short-acting molecules and may be divided into two main subgroups, namely pro-inflammatory cytokines (including TNF- $\alpha$ and IL-1 $\beta$ ), which are produced predominantly by activated macrophages and anti-inflammatory cytokines (e.g., IL-10) that suppress the inflammatory response (46).

TNF- $\alpha$, produced by a variety of cells, acts on its receptors and activates multiple signal pathways, such as death and survival pathways, and NADPH oxidase activation. NADPH oxidase produces superoxide, which immediately responds to NO, generating the strong oxidant peroxynitrite. Furthermore, TNF $\alpha$ impedes the eNOS promoter and leads to the destabilization of eNOS mRNA, consequently decreasing eNOS protein levels and the ability of the endothelium to yield NO $(47,48)$. Aortic ring experimentation has demonstrated that TNF- $\alpha$ reduces endothelium-dependent vasodilatation. Cytokine IL-10, as a noted key product of regulatory $\mathrm{T}$ cells (Tregs), exerts anti-inflammatory and, thus, protective effects in hypertension (49). It has also been demonstrated that boosted Treg function ameliorates Ang II and aldosterone-induced hypertension, cardiac fibrosis, coronary inflammation, electrical remodeling and impaired endothelial-dependent vasodilatation, which are possibly mediated at least partially by IL-10 release from Tregs (50). Previous studies $(32,51)$ have confirmed the key role of the balance between pro- and anti-inflammatory cytokines in cardiovascular remodeling and ED that often accompany hypertension, and restoring of this balance is crucial in the prevention of cardiovascular damage. Based on these findings, the present study demonstrated the presence of an immunological imbalance exists in the high salt-induced hypertensive mouse model, reflected by an increase in TNF- $\alpha$ and IL-1 $\beta$ and a decrease in IL-10 levels. Furthermore, treatment with XJEK restored the balance between pro- and anti-inflammatory status.

In conclusion, the present study demonstrated that the endothelial function in mice with hypertension induced by a high-salt diet resulted in cardiovascular remodeling and OS, which was reversed by XJEK or irbesartan treatment. Although XJEK possesses similar protective properties to those of irbesartan, XJEK is more effective in reducing blood pressure, and it possibly serves a role in attenuating vascular OS and inflammation and improving ACh-induced vasorelaxation and ED. Hence, it may be concluded that XJEK was able to suppress hypertension-induced damage in a high salt-induced hypertensive mouse model by ameliorating ED, and the underlying mechanisms may include restoring the balance between vasodilation and vasoconstriction factors, immunological balance and downregulating OS. Further research is required to fully elucidate the possible mechanisms and potential therapeutic implications of these findings.

\section{Acknowledgements}

Not applicable.

\section{Funding}

The present study was supported by grants from the National Natural Science Foundation of China (grant no. 81373774) and Anhui Medical University Foundation for Middle-aged and Young Scientist Leaders of Disciplines in Science (grant no. 201324). 

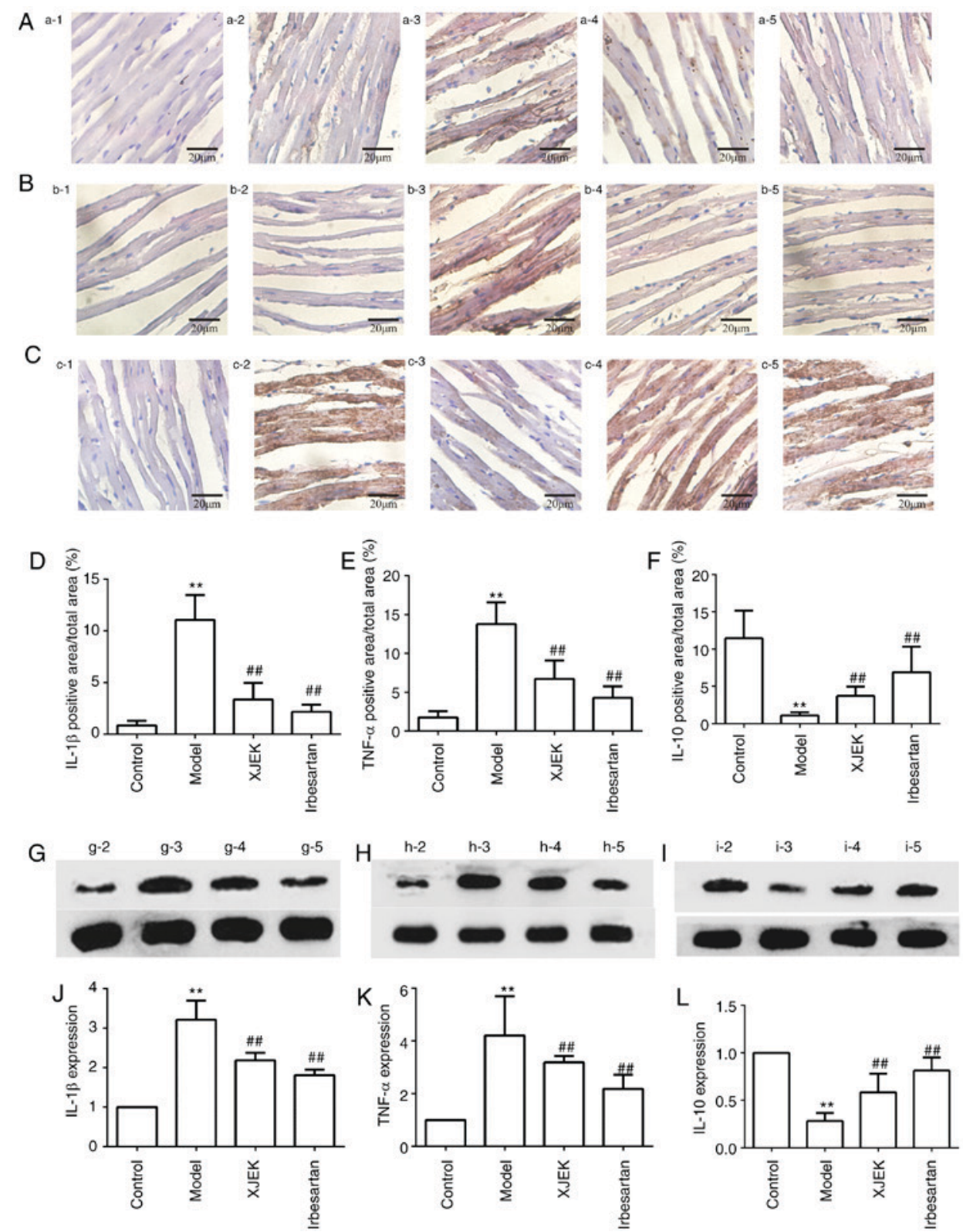

Figure 8. Effects of XJEK on IL-1 $\beta, T N F-\alpha$ and IL-10 in high-salt induced hypertensive mice. (A) Representative images of IL-1 $\beta$ immunohistological staining in heart (magnification, $x 400$ ). (B) Representative images of TNF- $\alpha$ immunohistological staining in heart (magnification, $x 400$ ). (C) Representative images of IL-10 immunohistological staining in heart (magnification, $x 400$ ). Quantified results of (D) IL-1 $\beta$, (E) TNF- $\alpha$ and (F) IL-10 immunohistological staining (n=10). (G-I) Representative figures of (G) IL-1 $\beta,(H)$ TNF- $\alpha$ and (I) IL-10 protein via western blotting. Quantitative analyses of (J) IL-1 $\beta$, (K) TNF- $\alpha$ and (L) IL-10 protein. 1: Negative group; 2: Control group; 3: Model group; 4: XJEK + high-salt-treated group; 5: Irbesartan + high-salt-treated group. Data are presented as the mean \pm standard deviation. ${ }^{* *} \mathrm{P}<0.01$ vs. control group; ${ }^{\# \#} \mathrm{P}<0.01$ vs. model group. XJEK, Xin-Ji-Er-Kang; IL, interleukin; TNF, tumor necrosis factor.
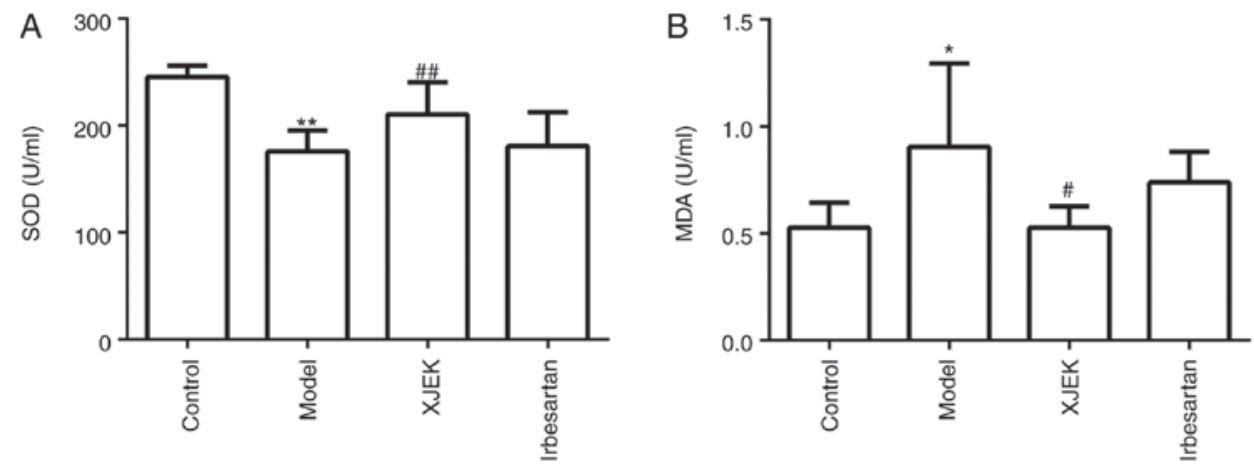

Figure 9. Effects of XJEK on serum (A) SOD and (B) MDA content in high-salt induced hypertensive mice. Data are presented as the mean \pm standard deviation, $\mathrm{n}=10 .{ }^{*} \mathrm{P}<0.05,{ }^{* *} \mathrm{P}<0.01$ vs. control group; ${ }^{*} \mathrm{P}<0.05,{ }^{\# t} \mathrm{P}<0.01$ vs. model group. XJEK, Xin-Ji-Er-Kang; SOD, superoxide dismutase; MDA, malondialdehyde. 


\section{Availability of data and materials}

The datasets used and/or analyzed during the current study are available from the corresponding author on reasonable request.

\section{Authors' contributions}

GH and PC performed the experiments. SG and AS supervised the design of the entire experiment and collaborated in the discussion of the results. GH wrote and revised the manuscript. LD, LW and JH helped analyze the experimental data. YZ, GC and MC interpreted the data and revised the manuscript. All authors read and approved the fnal version of the manuscript for publication.

\section{Ethics approval and consent to participate}

All the animals were handled strictly according to the rules and regulations outlined in the National Institutes of Health Guide for the Care and Use of Laboratory Animals (NIH Publications no. 8023, revision 1978), and approval was granted from the Animal Care and Use Committee of Anhui Medical University (Hefei, China). In this study, no peritonitis was observed in animals following intraperitoneal injection of $10 \%$ chloral hydrate and no other abnormal symptoms were found.

\section{Patient consent for publication}

Not applicable.

\section{Competing interests}

The authors declare that they have no competing interests.

\section{References}

1. Glover M, Zuber AM and O'Shaughnessy KM: Hypertension, dietary salt intake, and the role of the thiazide-sensitive sodium chloride transporter NCCT. Cardiovasc Ther 29: 68-76, 2011.

2. Lloyd-Jones D, Adams R, Carnethon M, De Simone G, Ferguson TB, Flegal K, Ford E, Furie K, Go A, Greenlund K, et al: Heart disease and stroke statistics-2009 update: A report from the American Heart Association Statistics Committee and Stroke Statistics Subcommittee. Circulation 119: 480-486, 2009.

3. Asghar M, Tayebati SK, Lokhandwala MF and Hussain T: Potential dopamine-1 receptor stimulation in hypertension management. Curr Hypertens Rep 13: 294-302, 2011.

4. Basson J, Simino J and Rao DC: Between candidate genes and whole genomes: Time for alternative approaches in blood pressure genetics. Curr Hypertens Rep 14: 46-61, 2012.

5. Lev-Ran A and Porta M: Salt and hypertension: A phylogenetic perspective. Diabetes Metab Res Rev 21: 118-131, 2005.

6. Drenjančević-Perić I, Jelaković B, Lombard JH, Kunert MP, Kibel A and Gros M: High-salt diet and hypertension: Focus on the renin-angiotensin system. Kidney Blood Press Res 34: 1-11, 2011.

7. Oloyo AK, Sofola OA and Yakubu MA: Orchidectomy attenuates high-salt diet-induced increases in blood pressure, renovascular resistance, and hind limb vascular dysfunction: Role of testosterone. Clin Exp Pharmacol Physiol 43: 825-833, 2016.

8. Guo K, Lan CZ, Yu TT, Huang LL, Wang XH, Pan C and Gao S: Effects of Xin-Ji-Er-Kang formula on 2K1C-induced hypertension and cardiovascular remodeling in rats. J Ethnopharmacol 155 $1227-1235,2014$

9. Boegehold MA, Drenjancevic I and Lombard JH: Salt, Angiotensin II, superoxide, and endothelial function. Compr Physiol 6: 215-254, 2015.
10. Roeleveld RJ, Vonk-Noordegraaf A, Marcus JT, Bronzwaer JG, Marques KM, Postmus PE and Boonstra A: Effects of epoprostenol on right ventricular hypertrophy and dilatation in pulmonary hypertension. Chest 125: 572-579, 2004.

11. Zhu J, Drenjancevic-Peric I, McEwen S, Friesema J, Schulta D, $\mathrm{Yu} \mathrm{M}$, Roman RJ and Lombard $\mathrm{JH}$ : Role of superoxide and angiotensin II suppression in salt-induced changes in endothelial $\mathrm{Ca} 2+$ signaling and NO production in rat aorta. Am J Physiol Heart Circ Physiol 291: H929-H938, 2006.

12. Zhu J, Mori T, Huang T and Lombard JH: Effect of high-salt diet on NO release and superoxide production in rat aorta. Am J Physiol Heart Circ Physiol 286: H575-H583, 2004.

13. Li L, Fink GD, Watts SW, Northcott CA, Galligan JJ, Pagano PJ and Chen AF: Endothelin-1 increases vascular superoxide via endothelin(A)-NADPH oxidase pathway in low-renin hypertension. Circulation 107: 1053-1058, 2003.

14. Pagano PJ, Clark JK, Cifuentes-Pagano ME, Clark SM, Callis GM and Quinn MT: Localization of a constitutively active, phagocyte-like NADPH oxidase in rabbit aortic adventitia: Enhancement by angiotensin II. Proc Natl Acad Sci USA 94: 14483-14488, 1997.

15. Rajagopalan S, Kurz S, Münzel T, Tarpey M, Freeman BA, Griendling KK and Harrison DG: Angiotensin II-mediated hypertension in the rat increases vascular superoxide production via membrane NADH/NADPH oxidase activation. Contribution to alterations of vasomotor tone. J Clin Invest 97: 1916-1923, 1996.

16. De Batista PR, Palacios R, Martin A, Hernanz R, Médici CT, Silva MA, Rossi EM, Aguado A, Vassallo DV, Salaices M and Alonso MJ: Toll-like receptor 4 upregulation by angiotensin II contributes to hypertension and vascular dysfunction through reactive oxygen species production. PLoS One 9: e104020, 2014.

17. Harrison DG, Marvar PJ and Titze JM: Vascular inflammatory cells in hypertension. Front Physiol 3: 128, 2012.

18. Matsusaka T and Ichikawa I: Biological functions of angiotensin and its receptors. Annu Rev Physiol 59: 395-412, 1997.

19. Cai H and Harrison DG: Endothelial dysfunction in cardiovascular diseases: The role of oxidant stress. Circ Res 87: 840-844, 2000.

20. Mehta PK and Griendling KK: Angiotensin II cell signaling: Physiological and pathological effects in the cardiovascular system. Am J Physiol Cell Physiol 292: C82-C97, 2007.

21. Chen LW, Qin KM,Zhu YH, Cai H, Li WD and Cai BC: Research status and prospect of primary processing of traditional Chinese medicinal materials. Zhongguo Zhong Yao Za Zhi 40: 602-606, 2015 (In Chinese).

22. Wang QM, Chen GL, Wang YJ, Wang HS, Gao MH and Gong YZ: An experimental study on inhibitory effect of xinjierkang granules on virus myocarditis. Zhongguo Zhong Yao Za Zhi 25: 293-296, 2000 (In Chinese).

23. U.S Department of Health Education \& Welfare: Guide for the care and use of laboratory animals (revised edition). 1978.

24. Preuss HG, Knapka JJ, MacArthy P, Yousufi AK, Sabnis SG and Antonovych TT: High sucrose diets increase blood pressure of both salt-sensitive and salt-resistant rats. Am J Hypertens 5: 585-591, 1992.

25. Yu TT, Guo K, Chen HC, Lan CZ, Wang J, Huang LL, Wang XH, Zhang Z and Gao S: Effects of traditional Chinese medicine Xin-Ji-Er-Kang formula on 2K1C hypertensive rats: Role of oxidative stress and endothelial dysfunction. BMC Complement Altern Med 13: 173, 2013.

26. Veltkamp R, Rajapakse N, Robins G, Puskar M, Shimizu K and Busija D: Transient focal ischemia increases endothelial nitric oxide synthase in cerebral blood vessels. Stroke 33: 2704-2710, 2002.

27. Ma S, Wang Q, Zhang Y, Yang D, Li D, Tang B and Yang Y: Transgenic overexpression of uncoupling protein 2 attenuates salt-induced vascular dysfunction by inhibition of oxidative stress. Am J Hypertens 27: 345-354, 2014.

28. Channon KM: Tetrahydrobiopterin: A vascular redox target to improve endothelial function. Curr Vasc Pharmacol 10: 705-708, 2012.

29. Gu JW, Bailey AP, Tan W, Shparago M and Young E: Long-term high salt diet causes hypertension and decreases renal expression of vascular endothelial growth factor in sprague-dawley rats. J Am Soc Hypertens 2: 275-285, 2008.

30. Jian W, Enze C and Lizhi L: Xin Ji Er Kang in Coronary Heart Disease. J NanJing Univ Trad Chin Med 14: 201-212, 1998 (in Chinese) 
31. Gao S, Wang XH, Huang LL, Yu TT, Du SM, Guo YW, Jia Y and Wang J: Effects of a compound Chinese medicine Xinji erkang on isoproterenol-induced ventricular remodeling in mice. Zhong Xi Yi Jie He Xue Bao 10: 330-336, 2012 (In Chinese).

32. Hu J, Zhang YX, Wang L, Ding L, Huang GY, Cai GW and Gao S: Protective effects of Xinji'erkang on myocardial infarction induced cardiac injury in mice. BMC Complement Altern Med 17: 338, 2017

33. Kazmi RS, Boyce S and Lwaleed BA: Homeostasis of hemostasis: The role of endothelium. Semin Thromb Hemost 41: 549-555, 2015.

34. Bunbupha S, Pakdeechote P, Kukongviriyapan U, Prachaney P and Kukongviriyapan V: Asiatic acid reduces blood pressure by enhancing nitric oxide bioavailability with modulation of eNOS and $\mathrm{p} 47$ phox expression in L-NAME-induced hypertensive rats. Phytother Res 28: 1506-1512, 2014.

35. Fu JY, Qian LB, Zhu LG, Liang HT, Tan YN, Lu HT, Lu JF, Wang HP and Xia Q: Betulinic acid ameliorates endothelium-dependent relaxation in L-NAME-induced hypertensive rats by reducing oxidative stress. Eur J Pharm Sci 44: 385-391, 2011.

36. Zatz R and Baylis C: Chronic nitric oxide inhibition model six years on. Hypertension 32: 958-964, 1998.

37. Shao Y, Cheng Z, Li X, Chernaya V, Wang H and Yang XF: Immunosuppressive/anti-inflammatory cytokines directly and indirectly inhibit endothelial dysfunction-a novel mechanism for maintaining vascular function. J Hematol Oncol 7: 80, 2014.

38. Amiri F, Ko EA, Javeshghani D, Reudelhuber TL and Schiffrin EL: Deleterious combined effects of salt-loading and endothelial cell restricted endothelin-1 overexpression on blood pressure and vascular function in mice. J Hypertens 28: 1243-1251, 2010.

39. O'Donnell M, Mente A, Rangarajan S, McQueen MJ, Wang X, Liu L, Yan H, Lee SF, Mony P, Devanath A, et al: Urinary sodium and potassium excretion, mortality, and cardiovascular events. N Engl J Med 371: 612-623, 2014.

40. Lagerqvist EL, Finnin BA, Pouton CW and Haynes JM: Endothelin-1 and angiotensin II modulate rate and contraction amplitude in a subpopulation of mouse embryonic stem cell-derived cardiomyocyte-containing bodies. Stem Cell Res 6 : 23-33, 2011.

41. Tsai IJ, Croft KD, Puddey IB, Beilin LJ and Barden A: 20-Hydroxyeicosatetraenoic acid synthesis is increased in human neutrophils and platelets by angiotensin II and endothelin-1. Am J Physiol Heart Circ Physiol 300: H1194-H1200, 2011.
42. Nurkiewicz TR, Wu G, Li P and Boegehold MA: Decreased arteriolar tetrahydrobiopterin is linked to superoxide generation from nitric oxide synthase in mice fed high salt. Microcirculation 17: $147-157,2010$

43. Channon KM: Tetrahydrobiopterin: Regulator of endothelial nitric oxide synthase in vascular disease. Trends Cardiovasc Med 14: 323-327, 2004.

44. Campbell DJ: Do intravenous and subcutaneous angiotensin II increase blood pressure by different mechanisms? Clin Exp Pharmacol Physiol 40: 560-570, 2013.

45. Androulakis ES, Tousoulis D, Papageorgiou N, Tsioufis C, Kallikazaros I and Stefanadis C: Essential hypertension: Is there a role for inflammatory mechanisms? Cardiol Rev 17: 216-221, 2009.

46. Sprague AH and Khalil RA: Inflammatory cytokines in vascular dysfunction and vascular disease. Biochem Pharmacol 78: 539-552, 2009.

47. Alonso J, Sánchez de Miguel L, Montón M, Casado S and López-Farré A: Endothelial cytosolic proteins bind to the 3' untranslated region of endothelial nitric oxide synthase mRNA: Regulation by tumor necrosis factor alpha. Mol Cell Biol 17: 5719-5726, 1997 .

48. Neumann P, Gertzberg N and Johnson A: TNF-alpha induces a decrease in eNOS promoter activity. Am J Physiol Lung Cell Mol Physiol 286: L452-L459, 2004.

49. Ren B and She Q: Study on the association between IL-1 1 , IL-8 and IL-10 gene polymorphisms and risk of coronary artery disease. Int J Clin Exp Med 8: 7937-7943, 2015

50. Kasal DA, Barhoumi T, Li MW, Yamamoto N, Zdanovich E, Rehman A, Neves MF, Laurant P, Paradis P and Schiffrin EL: $T$ regulatory lymphocytes prevent aldosterone-induced vascular injury. Hypertension 59: 324-330, 2012.

51. Schiffrin EL: Peroxisome proliferator-activated receptors and cardiovascular remodeling. Am J Physiol Heart Circ Physiol 288: H1037-H1043, 2005.

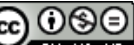

This work is licensed under a Creative Commons Attribution-NonCommercial-NoDerivatives 4.0 International (CC BY-NC-ND 4.0) License. 